\title{
Development of a Conceptual Model and Questionnaire of Principled Negotiation
}

\author{
Shougang Zhang ${ }^{1,2}$, Milan Constantinovits ${ }^{3}$ \\ ${ }^{1}$ School of Management and Business Administration, Szent István University, Gödöllő, Hungary \\ ${ }^{2}$ School of Business, Xi'an Siyuan University, Xi'an, China \\ ${ }^{3}$ Szent István University of Economics and Social Sciences, Gödöllö, Hungary
}

Objectives: Principled negotiation, proposed by Fisher and Ury, is a tool used in many disputes, but it has received some criticism, especially for its lack of empirical evidence. In this paper, we use an empirical method to study the principled negotiation model and develop a questionnaire of principled negotiation.

Methods: Firstly, we build a conceptual model of principled negotiation and propose the hypothesis that the principled negotiation model is constituted of four dimensions-the adult-ego people, harmonious interest, creative options, and fair criteria. Secondly, we develop a questionnaire of principled negotiation with the procedures and principles of scientific scale development. Lastly, through a survey of Chinese college students in China and data analysis, we confirm our hypothesis by using item analysis, reliability analysis, and validity analysis.

Results: The results of our exploratory research of the principled negotiation model are ideal, and the obtained four-factor model can reasonably fit the data. The validity of this questionnaire is found to be good, and the questionnaire of principled negotiation passes the tests of reliability and validity.

Conclusions: The main variables of the questionnaire of principled negotiation were identified by applying a logical approach. The four dimensions (people, interests, options, and criteria) were obtained from the literature and an in-depth quantitative assessment. This questionnaire of principled negotiation can provide a practical guide for negotiators and researchers who wish to use a scientific measuring tool.

Key Words: Conceptual Model, Questionnaire, Principled Negotiation, Exploratory Factor Analysis, Instrument Development

\section{Introduction}

\section{Background}

Principled negotiation was developed by Professor Roger Fisher,

Received: Apr 26, 2018 Revised: Jun 25, 2018 Accepted: Jul 1, 2018

Corresponding author: Shougang Zhang

School of Management and Business Administration,

Szent István University, Páter Károly utca 1,Gödöllö 2100, Hungary

Tel: +36702195028, E-mail: zsg771126@gmail.com

This is an Open Access article distributed under the terms of the Creative Commons Attribution Non-Commercial License (http://creativecommons.org/licenses/ by-nc/4.0/) which permits unrestricted non-commercial use, distribution, and reproduction in any medium, provided the original work is properly cited.

Copyright $\odot 2018$ Korean Association for Business Communication. who taught at Harvard Law School, and William Ury in 1981 in their book Getting to Yes: Negotiating Agreement without Giving In, the negotiation classic that stayed on the Business Week bestseller list for a year. For over thirty years, the method of principled negotiation has been the dominant formative approach to negotiation around the world and has become an important guiding principle in international negotiation for handling disputes and resolving conflicts.

Fisher and Ury (1981) thought principled negotiation was superior to positional bargaining or win-lose results. The method of principled negotiation has been used in a wide variety of disputes since its initial development. Examples include 
conflict resolution (Arnold \& Kendall, 2008), decision support (Carneiro, Novais, Andrade, Zeleznikow, \& Neves, 2013), and social work (Lens, 2004). The book is easy to understand and contains an impressive number of stories and cases but has received some criticism in academic circles because its authors do not give empirical evidence but rather stories of what they experienced or heard (Zhang \& Constantinovits, 2016). Therefore, in this paper, we use an empirical method to study principled negotiation.

Much of the empirical research is conducted in field settings where the most commonly used method of data collection is the survey questionnaire. In order to conduct an empirical study of principled negotiation, we have reviewed various well-known databases (e.g., Web of Science, Emerald, Sage, EBSCO, Scopus), but we have not found any relevant literature on principled negotiation questionnaires. Many instances exist in which the researcher cannot find an adequate or appropriate existing scale to measure an important construct. In these situations, it is necessary to create a new scale (Hinkin, Tracey, \& Enz, 1997).

\section{A Conceptual Framework of Principled Negotiation}

Fisher and Ury (1981) considered principled negotiation to be a third way in addition to soft negotiation and hard negotiation. Ideally, if both sides of negotiators follow the four main points of principled negotiation (i.e., separating the people from the problem; focusing on interests, not positions; inventing options for mutual gain; and insisting on objective criteria), the negotiations will result in an amicable agreement. Following these points, we propose a conceptual framework of principled negotiation.

\section{The Adult Ego People}

Negotiators are people first (Fisher \& Ury, 1981). Nowadays, the central issues in negotiation studies deal with the question of how the negotiation process influences negotiation outcomes. Due to the complexities of determining the negotiation process and the negotiation outcomes, scholars generally find that these issues rely on psychological concepts such as individual differences, behaviour characteristics, and the cognitive state of negotiators (Bazerman, Curhan, Moore, \& Valley, 2000). Transactional analysis is a branch of psychology founded by Canadian-born and American-based psychiatrist Eric Berne. His definition of transactional analysis is "a theory of personality and a systematic psychotherapy for personal growth and change" (Berne, 1968). In Berne's model, there are three ego states: Parent, Adult, and Child. The Parent and Child ego states are echoes of the past. The Adult ego state is a response to the here and now when a person is grown up and using grown up responses. When a negotiator uses principled negotiation, he or she is considered to be in the adult ego state (Zhang \& Constantinovits, 2017).

\section{The Harmonious Interest}

Fisher and Ury (1981) propose that we reconcile interests, not positions. Principled negotiation pursues a win-win negotiation. The result of a win-win negotiation is that all parties in the negotiation can pursue their respective interests through the negotiation. According to Zhang and Constantinovits (2016), the ultimate objective of negotiation is to set up equilibrium and harmony based on Chinese harmony thought. Harmony can be interpreted as the ideological concepts of conscientiousness, concordance, peacefulness, and gentleness. Principled negotiation is similar to the concept of Tai Chi negotiation (harmony negotiation). Rationality should not inhibit feeling, and sensitivity should not obstruct intelligence. The movement of Yin and Yang is the ability to listen and speak and to follow a partner's line of argumentation but depart from one's own central points (Zhang \& Constantinovits, 2016).

\section{The Creative Options}

Fisher and Ury (1981) stress the importance of inventing options for mutual gain. Negotiation is a process of continuously creating alternatives. In the preparation phase of a negotiation, it is necessary to prepare for the various options that may be encountered and even a BATNA (Best Alternative to a Negotiated Agreement) in the case of an unsuccessful negotiation. Negotiators with a BATNA have reported higher individual outcomes and percentages of the dyadic outcomes than individuals without a BATNA (Roloff \& Dailey, 1987). In order to obtain creative solutions, we must abandon premature judgements, the search for a single answer, and the assumption of a fixed pie (Fisher \& Ury, 1981).

\section{The Fair Criteria}

When you use the above three rules to deal with conflicts, sometimes resolution is not possible. You must use the fair criteria to solve this problem. The negotiator engages in quotations, counter-offers, and the decision to conclude a deal or abandon the transaction based on a fair understanding of the negotiation (Welsh, 2003). In order to seek fair results in the negotiation, these criteria can be expressed as legal regulations, general rules, business practices, industry standards, scientific calculation methods, accepted assessment methods, or third-party appraisals.

In conclusion, we formally put forward the following theoretical assumptions: Principled negotiation includes people, interests, options, and criteria. According to our hypothesis, we 


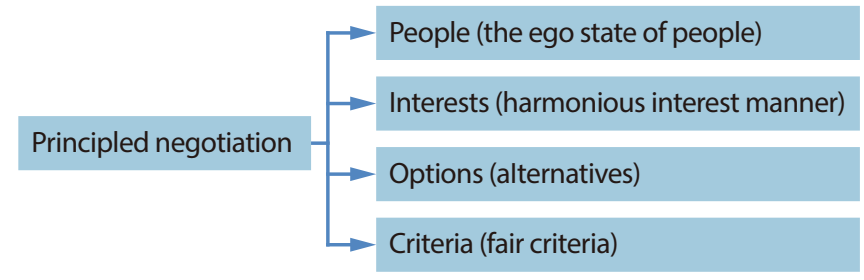

Figure 1. Conceptual framework of principled negotiation.

set up a conceptual model shown in Figure 1.

\section{Methods}

A mixed qualitative-quantitative approach was used to develop a conceptual model (Azmal, Sari, Foroushani, \& Ahmadi, 2016). This study was implemented in three steps: (1) Identifying items of the principled negotiation questionnaire through a comprehensive literature review and interviews, (2) Choosing a pilot test sample, and (3) Developing a principled negotiation questionnaire using item analysis, reliability analysis, and validity analysis. We used two software programs, including IBM SPSS Statistics (Version 22.0) and Excel.

\section{Step One: Literature Review and Interviews with the Initial Questionnaire}

Because we could not find direct studies of questionnaires based on principled negotiation, the information gathered from studies was retrieved based on a synthesis of relevant information sources. We referred to a questionnaire of transactional analysis (McCormick, 1971), a questionnaire of subjective value in negotiation (Curhan, Elfenbein, \& Xu, 2006), the Negotiations Self-Assessment Inventory Questionnaire (Tero International, 2014), and the Negotiation Skills Questionnaire (Cook, 2015). At the end of this step, the premature items were identified and classified.

The qualitative method in the semi-structured interviews was used to assess the principled negotiation questionnaire and to identify the characteristics of the context. We invited 5 doctoral students and 4 teachers in business administration of Xian Jiaotong University to discuss them and compress and summarize the 67 items. After this procedure, 55 items remained. Then, a professor of management, a Chinese Ph.D., 4 associate professors in management, two lecturers in management, and six staff members with more than five years of work experience related to these topics discussed the expression and popularity of each item. According to their suggestions, 55 items were then compressed again to 40 items, and questions with a 7-point Likert scale were ultimately designed to extract the dimensions, and the 40 items were used as the questions for the pre-test questionnaire.

\section{Step Two: Pilot Test Sample}

In this study, 105 undergraduate students who study in Capital University of Economics and Business, Beijing Jiaotong University, Beijing Technology and Business University, and China University of Political Science and Law were given questionnaires, which resulted in 96 valid questionnaires, 9 invalid questionnaires (an effective recovery rate of 91.4\%). After the significance test, the above samples showed no significant difference between men and women. First, the 105 valid questionnaires were selected directly in response to " 4 (cannot be judged)," which resulted in a total of 4 being deleted. For the remaining 32 items, the items were renumbered to form the second pre-test questionnaire, using a Likert 7-point scale, and the answer was not set in the middle of "cannot be determined," as we wished to avoid the adverse influence of "neutrality" in the answers.

\section{Step Three: Final Sample for Reliability and Validation of the Questionnaire}

It appears that the number of variables or items to be assessed will dictate the sample size needed to obtain robust results. Earlier recommendations for item-to-response ratios ranged from 1:4 (Rummel, 1970) to at least 1:10 (Schwab, 1980). The final sample consisted of 229 students who were studying at 27 universities in China. The students were asked to respond to a 32item questionnaire between August and October 2017. Among these survey samples, 204 responses were completed, and the analysis of reliability and validation required a minimum sample size of 5-10 times the number of items. The current sample size of 229 observations (for 32 items) met this criterion. Item analysis was measured using the independent $t$-tests. To assess the reliability of the questionnaire, Cronbach's alpha was used. Validity also was measured by Exploratory Factor Analysis (EFA) applying SPSS software.

\section{Results}

\section{Item Analysis}

First, we calculated the total score of each subject, taking $27 \%$ of the subjects with high and low-with below $27 \%$ as low groups and over $27 \%$ as high groups. An independent $t$-test was performed on the questionnaire data of the two groups. By looking at the value of significance, if this was greater than 0.05 , it was considered to show no difference. If it was less than 0.05 , the difference was considered marked and an indicator of the good discrimination of the items (Guo, 2015). The results of the anal- 
Table 1. Item analysis using independent $t$-test for the initial questionnaire of principled negotiation

\begin{tabular}{lccccccccccc}
\hline Item & $\boldsymbol{t}$ & $\boldsymbol{P}>|\boldsymbol{t}|$ & Item & $\boldsymbol{t}$ & $\boldsymbol{P}>|\boldsymbol{t}|$ & Item & $\boldsymbol{t}$ & $\boldsymbol{P}>|\boldsymbol{t}|$ & Item & $\boldsymbol{P}>|\boldsymbol{t}|$ \\
\hline PN01 & -7.34 & $<.001$ & PN09 & -11.81 & $<.001$ & PN17 & -8.43 & $<.001$ & PN25 & -9.60 & $<.001$ \\
PN02 & -8.05 & $<.001$ & PN10 & -9.32 & $<.001$ & PN18 & -7.61 & $<.001$ & PN26 & -8.42 & $<.001$ \\
PN03 & -8.40 & $<.001$ & PN11 & -9.05 & $<.001$ & PN19 & -8.81 & $<.001$ & PN27 & -9.37 & $<.001$ \\
PN04 & -7.63 & $<.001$ & PN12 & -10.04 & $<.001$ & PN20 & -7.58 & $<.001$ & PN28 & -7.73 & $<.001$ \\
PN05 & -7.06 & $<.001$ & PN13 & -10.16 & $<.001$ & PN21 & -10.01 & $<.001$ & PN29 & -10.16 & $<.001$ \\
PN06 & -6.19 & $<.001$ & PN14 & -8.14 & $<.001$ & PN22 & -8.19 & $<.001$ & PN30 & -12.91 & $<.001$ \\
PN07 & -8.64 & $<.001$ & PN15 & -6.43 & $<.001$ & PN23 & -10.05 & $<.001$ & PN31 & -11.21 & $<.001$ \\
PN08 & -5.83 & $<.001$ & PN16 & -8.30 & $<.001$ & PN24 & -11.66 & $<.001$ & PN32 & -8.91 & $<.001$ \\
\hline
\end{tabular}

Note. $\mathrm{PN}=$ principled negotiation.

ysis showed that the $p$-value of all the items is less than 0.05 (as shown in Table 1). Therefore, the difference between the two means is statistically significantly different from zero at the $5 \%$ level of significance. However, there is sufficient evidence $(p<$ $.001)$ to suggest that items of principled negotiation are good discriminators.

\section{Reliability Analysis}

Reliability mainly refers to the reliability, consistency, and stability of the measurement results, that is, whether the test results reflect the stable, real characteristics of the subjects (Field, 2013). SPSS offers procedure reliability to perform an item analysis. These can be requested with the following. At present, Cronbach's alpha is the most commonly used, and the internal reliability of the scale is generally considered. The reliability coefficient should be between 0 and 1 . If the reliability coefficient is greater than 0.9 , the reliability is excellent; if the reliability coefficient is between 0.8 and 0.9 , the reliability is good; if the reliability coefficient is between 0.7 and 0.8 , the reliability is acceptable; if the reliability coefficient is between 0.6 and 0.7 , the reliability is questionable; if the reliability coefficient is between 0.5 and 0.6 , the reliability is poor; if the reliability coefficient is below 0.5, it needs to be discarded (Bland \& Altman, 1997). The results are shown in Table 2.

\section{Validity Analysis}

Exploratory Factor Analysis (EFA) is a statistical approach for determining the correlation among the variables in a dataset (Fabrigar \& Wegener, 2011). This type of analysis provides a factor structure (a grouping of variables based on strong correlations). Before EFA, KMO (Kaiser-Meyer-Olkin) and Bartlett need to be performed on each variable to see if it is suitable for EFA. It is generally acknowledged that a KMO value greater than 0.7 is suitable for EFA, and the Bartlett sphere test value should be within a significance level of 0.05 (Norusis, 1994).
The KMO in EFA in the new model was 0.891. After constant adjustment (deleting), the new model for the questionnaire of

Table 2. Reliability statistic of four dimensions in the initial questionnaire of principled negotiation

\begin{tabular}{lcc}
\hline Dimension & Number of items & Cronbach's alpha \\
\hline People & 7 & .643 \\
Interests & 11 & .851 \\
Options & 8 & .790 \\
Criteria & 6 & .785 \\
\hline
\end{tabular}

Table 3. Exploratory factor analysis with varimax rotation for 18 items in the questionnaire of principled negotiation

\begin{tabular}{lcccc}
\hline Item & Factor 1 & Factor 2 & Factor 3 & Factor 4 \\
\hline PN16 & 0.77 & & & \\
PN18 & 0.68 & & & \\
PN26 & 0.67 & & & \\
PN28 & 0.63 & & & \\
PN07 & 0.50 & & & \\
PN13 & 0.43 & & & \\
PN17 & & 0.83 & & \\
PN11 & & 0.71 & & \\
PN19 & & 0.66 & & \\
PN30 & & 0.66 & & \\
PN22 & & 0.56 & & \\
PN05 & & & 0.83 & \\
PN06 & & & 0.64 & \\
PN10 & & & 0.45 & \\
PN08 & & & 0.44 & \\
PN03 & & & & \\
PN01 & & & & \\
PN02 & & & & \\
\hline & & & & \\
\hline
\end{tabular}

Note. $\mathrm{PN}=$ principled negotiation. 
Table 4. The final 18-item questionnaire of principled negotiation

\begin{tabular}{|c|c|c|}
\hline Dimension & Item & Description \\
\hline \multirow[t]{5}{*}{ People } & PN17 & I am a person who is more rational than emotional. \\
\hline & PN11 & I always collect enough information before making a judgment. \\
\hline & PN19 & I have been able to I use my time very well. \\
\hline & PN30 & I am a person who often reads books. \\
\hline & PN22 & I will habitually predict a possible outcome before something is put into action. \\
\hline \multirow[t]{6}{*}{ Interests } & PN16 & I understand that others' interests need to be diverse, not specific, not clear. \\
\hline & PN18 & When negotiating, I can accurately and clearly express my own interests and needs. \\
\hline & PN26 & When negotiating, I am good at grasping the consensus to find common interests. \\
\hline & PN28 & When the negotiations diverge, I do not argue with others about what has happened but rather to influence the future. \\
\hline & PN07 & I am good at converting my interest demands into multiple sets of executable alternatives. \\
\hline & PN13 & When negotiating, I can stick to my own interests while not attacking or accusing others. \\
\hline \multirow[t]{4}{*}{ Options } & PN05 & I often ask myself and the other "why" to explore the interests of others. \\
\hline & PN06 & I always prepare a different alternative program before the negotiations. \\
\hline & PN10 & I call different experts to look at the problem. \\
\hline & PN08 & I try to find a solution that is also satisfactory to others. \\
\hline \multirow[t]{3}{*}{ Criteria } & PN03 & I often think about value and meaning when doing things. \\
\hline & PN01 & $\begin{array}{l}\text { When I encounter a problem or cannot persuade others, I will first call experienced people (experts) for help dealing } \\
\text { with the problem. }\end{array}$ \\
\hline & PN02 & I often ask others what their views and theories are based on. \\
\hline
\end{tabular}

Note. $\mathrm{PN}=$ principled negotiation.

principled negotiation measure in this study was identified by four interrelated constructs (Table 3).

Based on the above research, the results of the exploratory research of the principled negotiation model were ideal, and the four-factor model obtained can fit the data reasonably well. The validity of this questionnaire was also good. The questionnaire of principled negotiation has thus far passed the tests of reliability and validity, and the formal questionnaire has been formed. At the same time, the conception model and hypothesis of principled negotiation in this study can be finally verified because the above four factors are consistent with the four-dimensional theory hypothesis of the principled negotiation model. This questionnaire consisted of 18 items evaluated using a 7-point Likert scale (from strongly disagree to strongly agree) to assess principled negotiation and 5 items for the people dimension, 6 items for the interests dimension, 4 items for the options dimension, and 3 items for the criteria dimension. The final questionnaire was developed as follows (Table 4).

\section{Discussion}

\section{Four Dimensions in Principled Negotiation}

The purpose of our research was to test a conception of principled negotiation and develop a questionnaire of principled negotiation. Specifically, we examined four dimensions of principled negotiation: people, interests, options, and criteria.

\section{People: The Adult Ego is the Basis of Principled Negotiation}

In the final questionnaire of principled negotiation, 6 items were extracted from behavioral characteristics of the adult ego. The Adult Ego State is the so-called "computer" part of us. With the Adult Ego State, an individual offers and asks for information, and based on the data, she makes decisions. The function of the State is a fact-based one. In the Adult Ego State, the person uses logical thinking to solve problems, being also a mediator between the Child Ego State and the Parent Ego State (Joines \& Stewart, 2007). These characteristics include personality traits, habits of reading and use of time, planned behavior, preparation, and predictive behavior. Our analysis showed that 6 items effectively reflect the behavioral characteristics that should be possessed when negotiating.

\section{Interests: Harmonious Interests are the Goal of Principled Negotiation}

As negotiations are mainly used to resolve conflicts of interest, 7 items were extracted from interest characteristics. According to Chinese thought, the ultimate objective of negotiation is to set up equilibrium and harmony (Zhang \& Constantinovits, 2016). 
To find a state of harmonious interests in principled negotiation, negotiators need to understand the complexity of the benefits, ask themselves and the other "why" to explore each other's interests, express their own interests clearly, seize their common interests, focus on future benefits, develop an executable benefit plan, and fight for their own interests but not attack others. Our analysis showed that 7 items reflect the interest characteristics that should be possessed when negotiating.

\section{Options: Creating Alternatives are the Key to Solving the Problem}

Conflicts of negotiation require creative alternatives. 3 items were extracted from the process of inventing options. Item 14 in the final questionnaire of principled negotiation emphasizes that various alternatives should be designed in the negotiation preparation phase. Item 15 in the final questionnaire of principled negotiation emphasizes that a brainstorming session is designed to produce as much as possible to solve the problem at hand. Item 16 in the final questionnaire of principled negotiation emphasizes that various alternatives should be designed to realize mutual gain. Our analysis showed that 3 items reflect the process of inventing options that should be possessed when negotiating.

\section{Criteria: Using Third-Party Forces to Promote Negotiations}

When negotiators encounter such a dilemma, they need to use third-party forces to promote negotiations. Item 17 in the final questionnaire of principled negotiation emphasizes the importance of looking for experienced experts who know market value, tradition, professional standards, and other relevant pieces of information. Item 18 in the final questionnaire of principled negotiation emphasizes that objective evidence should be sought. Our analysis showed that 2 items reflect the objective criteria that should be possessed when facing a conflict of interest.

\section{Limitations of the Study}

Before recommending that all negotiators and researchers use the questionnaire of principled negotiation, some factors must be considered. First, the research sample is relatively limited, as the participants were all college students in Chinese universities. The issue of homogeneity should be considered in future research, as the heterogeneity of the sample is an important factor affecting validity. Under the same conditions, the more homogeneous the sample group, the smaller the score distribution range and the lower the validity of the test. On the other hand, the more heterogeneous the sample group, the larger the score distribution range, and the higher the validity of the test. The research samples should not only be limited to the group of college students in Chinese universities but should be selected by people from all walks of life who engage in actual business negotiations. In order to break through national restrictions, future researchers should even choose a sample of international business negotiations to enrich the study.

Second, the results may not be exact because of the small sample size. The study participants consisted of college students. Subject to conditions, this study collected a total of 229 students studying at 27 universities in China as samples, and this sample size is small. A larger sample size would obviously help to improve the applicability of the research conclusions. We suggest that a conservative approach be adopted in the future. As sample size increases, the likelihood of attaining statistical significance increases.

Third, the limitation of the study is that it is discriminatory in regards to real negotiation. As students (with their age average being 20) are relatively unfamiliar with business situations and lack practical work experience, although oral explanations and written notices were given in the survey, some students still felt that they would not know what to do in the negotiation, which would affect the reliability of the data. In future studies, those who have negotiating experience should be involved in the research. Furthermore, as negotiation is a widespread phenomenon and its impact is not confined to China, the sample origin should be wider. Principled negotiation is an all-purpose strategy (Fisher \& Ury, 1981). A sample with a wider geographical distribution and more categories can be analyzed in more detail, and other valuable conclusions may be drawn.

Fourth, another limitation of this study is the measurement of principled negotiation. Although the principled negotiation scale currently used is still a better method than other research methods, it also has its drawbacks. For example, Cronbach's Alpha value of people should be 0.8 or higher at the individual level, but it is now 0.643 , which indicates a lack of reliability, leading to difficulties in interpreting the research results. Finding a method that can achieve a better measurement of the effects of principled negotiation should be the next step in the research. In scale development, a confirmatory factor analysis should be a confirmation that the prior analyses have been conducted thoroughly and appropriately, which should provide the researcher with the confidence that the finalized measures possess reliability and validity and are suitable for use in future research.

\section{Conclusions}

The widely-used measurement scale for principled negotiation, which has been criticized due to a lack of empirical evidence, 
was proposed and validated. A logical approach was adopted to identify the main variables of the questionnaire. The four dimensions (people, interests, options, and criteria) were obtained from the literature, and an in-depth quantitative assessment was conducted. This questionnaire of principled negotiation can provide a practical guide for negotiators and researchers who wish to use a scientific measuring tool.

\section{Acknowledgments}

One author, Shougang Zhang, was supported financially by China Scholarship Council (CSC NO.201500500079).

\section{References}

Arnold, R. M., \& Kendall, A. (2008). Conflict resolution II: Principled negotiation\#184. Journal of Palliative Medicine, 11(6), 926927.

Azmal, M., Sari, A. A., Foroushani, A. R., \& Ahmadi, B. (2016). Developing a conceptual model for the application of patient and public involvement in the healthcare system in Iran. Electronic Physician, 8(6), 2506-2514.

Bazerman, M. H., Curhan, J. R., Moore, D. A., \& Valley, K. L. (2000). Negotiation. Annual Review of Psychology, 51(1), 279-314.

Berne, E. (1968). Games people play: The psychology of human relationships. London, UK: Penguin.

Bland, J. M., \& Altman, D. G. (1997). Statistics notes: Cronbach's alpha. BMJ, 314(7080), 572.

Carneiro, D., Novais, P., Andrade, F., Zeleznikow, J., \& Neves, J. (2013). Using case-based reasoning and principled negotiation to provide decision support for dispute resolution. Knowledge and Information Systems, 36(3), 789-826.

Cook, S. (2015). Negotiation skills questionnaire. Retrieved from http://www.gpmfirst.com/sites/default/files/downloads/how_ am_i_-_interpersonal_07_negotiation_skills.pdf

Curhan, J. R., Elfenbein, H. A., \& Xu, H. (2006). What do people value when they negotiate? Mapping the domain of subjective value in negotiation. Journal of Personality and Social Psychology, 91(3), 493-512.

Fabrigar, L. R., \& Wegener, D. T. (2011). Exploratory factor analysis.
Ney York, NY: Oxford University Press.

Field, A. (2013). Discovering statistics using IBM SPSS statistics. London, UK: Sage.

Fisher, R., \& Ury, W. (1981). Getting to yes: Negotiating agreement without giving in (2nd ed.). New York, NY: Houghton Mifflin.

Guo, X. (2015). Construction and validation of the integration model of planned behavior theory and health belief model. Proceedings of the Ninth International Conference on Management Science and Engineering Management (pp. 151-160). Karlsruhe, Germany.

Hinkin, T. R., Tracey, J. B., \& Enz, C. A. (1997). Scale construction: Developing reliable and valid measurement instruments. Journal of Hospitality \& Tourism Research, 21(1), 100-120.

Joines, V., \& Stewart, I. (2007). Personality adaptations: A new guide to human understanding in psychotherapy and counselling. Princeton, NJ: Recording for the Blind \& Dyslexic.

Lens, V. (2004). Principled negotiation: A new tool for case advocacy. Social Work, 49(3), 506-513.

McCormick, P. (1971). Guide for use of a life-script questionnaire in transactional analysis. San Francisco, CA:Transactional Pubs.

Norusis, M. J. (1994). SPSS professional statistics, version 6.1 (SPSS for Windows 6.1). Chicago, IL: SPSS Inc.

Roloff, M. E., \& Dailey, W. O. (1987, May). The effects of alternatives to reaching agreement on the development of integrative solutions to problems: The debilitating side effects of shared BATNA. Paper presented at the Temple University Discourse Conference "Conflict Intervention: Perspectives on Process," Philadelphia, PA.

Rummel, R. J. (1970). Applied factor analysis. Evanston, IL: Northwestern University Press.

Schwab, D. P. (1980). Construct validity in organization behavior. Research Organizational Behavior, 2, 3-43.

Tero International. (2014). Negotiations self-assessment inventory. Retrieved from http://www.tero.com/pdfs/negassessment.pdf

Welsh, N. A. (2003). Perceptions of fairness in negotiation. Marquette Law Review, 87(4), 753-767.

Zhang, S., \& Constantinovits, M. (2016). A study of principled negotiation based on the chinese harmony thought. BRAND. Broad Research in Accounting, Negotiation, and Distribution, 7(1), 63-74.

Zhang, S., \& Constantinovits, M. (2017). A study of principled negotiation based on transactional analysis theory. BRAND. Broad Research in Accounting, Negotiation, and Distribution, 8(2), 3-10. 